Widya Cipta: Jurnal Sekretari dan Manajemen

Volume 4 No. 1 Maret 2020

P-ISSN 2550-0805 E-ISSN 2550-0791

https://doi.org/10.31294/widyacipta.v4i1

\title{
Pengaruh Pemberian Kompensasi terhadap Kinerja Karyawan Hotel Dafam Kota Pekalongan
}

\author{
Aria Mulyapradana ${ }^{1}$, Tri Rosewati ${ }^{2}$, Farikhul Muafiq $^{3}$ \\ 1,2,3 Politeknik Pusmanu \\ e-mail : ${ }^{1}$ ariamulyapradana@gmail.com, ${ }^{2}$ trirosewati2@gmail.com, ${ }^{3}$ farikhul@gmail.com

\begin{tabular}{ccc}
\hline Diterima & Direvisi & Disetujui \\
$26-12-2019$ & $15-01-2020$ & $29-01-2020$ \\
\hline
\end{tabular}

\begin{abstract}
Abstrak - Persaingan di era globalisasi yang semakin ketat perusahaan dituntut untuk dapat memenangkan persaingan bisnis dengan sehat. Keberhasilan suatu perusahaan ditentukan sejauh mana pimpinan menciptakan dan menghasilkan kinerja karyawan yang baik untuk mencapai tujuan yang telah ditentukan. Pemberian kompensasi merupakan salah satu kegiatan untuk meningkatkan kinerja karyawan. Kepuasan atas pemberian kompensasi oleh perusahaan dapat mempengaruhi karyawan untuk dapat bekerja lebih semangat agar tercapai tujuan perusahaan. Tujuan dari penelitian ini untuk menguji pengaruh pemberian kompensasi terhadap kinerja karyawan di Hotel Dafam Kota Pekalongan. Metode yang digunakan yaitu metode kuantitatif dengan menggunakan SPSS versi 16.0 dan metode pengumpulan data dengan cara observasi, wawancara dan menyebarkan kuesioner kepada karyawan Hotel Dafam Kota Pekalongan sejumlah 44 responden dengan menggunakan teknik sensus. Teknik pengumpulan data menggunakan kuesioner dengan skala likert, yang masing-masing telah diuji menggunakan validitas dan reliabilitas. Analisas data yang digunakankan analisis regresi linear sederhana dan pengujian hipotesis menggunakan uji t dapat dijeleskan bahwa ada pengaruh positif antara pemberian kompensasi terhadap kinerja karyawan di Hotel Dafam Kota Pekalongan.
\end{abstract}

Kata kunci: pemberian kompensasi; kinerja; karyawan

Abstract - Competition in the increasingly stringent era of globalization companies are required to be able to win business competition with a healthy. The success of a company is determined by the extent to which leaders create and produce good employee performance to achieve predetermined goals. Providing compensation is an activity to improve employee performance. Satisfaction with compensation given by the company can influence employees to work more enthusiastically to achieve company goals. The purpose of this study was to examine the effect of giving compensation to employee performance in Dafam Hotel, Pekalongan City. The method used is a quantitative method using SPSS version 16.0 and data collection methods by observation, interviews and distributing questionnaires to employees of the Dafam Hotel in Pekalongan City with a total of 44 respondents using census techniques. Data collection techniques using a questionnaire with a likert scale, each of which has been tested using validity and reliability. Analysis of the data used simple linear regression analysis and hypothesis testing using the t test can be concluded that there is a positive effect between the provision of compensation on employee performance in the Dafam Hotel, Pekalongan City.

Keywords: compensation; performance; employees

\section{PENDAHULUAN}

Di era globalisasi ini perusahaan diharapkan untuk dapat berkembang dan mengalami perubahan yang lebih baik karena peningkatan persaingan yang semakin ketat. Perusahaan yang tidak dapat berkembang dan tidak melakukan perubahaan secara tidak langsung akan tersingkir.

Hal ini terlihat pesatnya pertumbuhan hotel di Kota Pekalongan dan banyaknya wisatawan lokal maupun asing datang ke Kota Pekalongan sehingga persaingan pemberian pelayanan oleh karyawan harus 
ditingkatkan agar kualitas pelayanan yang diberikan tetap terjaga baik.

Guna mengatasi persaingan tersebut maka perusahaan berusaha untuk meningkatkan dan pengembangkan pelayanan dengan cara meningkatkan kinerja para karyawannya. Dengan meningkatkan kinerja karyawan diharapkan perusahaan dapat mewujudkan tujuan perusahaan yang ingin dicapainya dan memenangkan persaingan bisnis yang semakin ketat.

Pengelolaan sumber daya manusia merupakan hal yang harus diperhatikan oleh perusahaan agar menghasilkan kinerja karyawan yang optimal. Karyawan merupakan bagian yang terpenting dalam mencapai tujuan. Oleh Karena itu, perusahaan harus dapat mengelola karyawan dengan baik dan benar. Jika perusahaan tidak mengelola dengan baik dan benar maka tidak akan terwujudnya kinerja karyawan yang optimal dan tercapainya tujuan perusahaan. Permasalahan kinerja pun menjadi fenomena yang sangat menarik untuk diangkat karena menurut Hasibuan (Mujibul \& Hakim, 2019) kinerja yang buruk berakibat pada pencapaian waktu yang menurun dalam perusahaan.

Upaya perusahaan untuk meningkatkan kinerja karyawan agar mendapatkan hasil yang maksimal maka perusahaan melakukan beberapa kegiatan diantaranya pemberian kompensasi yang baik kepada karyawan. Meski kompensasi bukan satu-satunya yang mempengaruhi kinerja, tetapi hal itu merupakan salah satu faktor yang dapat menentukan dan mendorong kinerja karyawan. Jika karyawan merasa usahanya dihargai dan perusahaan menerapkan sistem kompensasi yang baik, umumnya karyawan tersebut akan termotivasi untuk meningkatkan kinerjanya.

Hal tersebut senada dengan hasil penelitian yang dilakukan oleh Ni Made Nurcahyani dan I.G.A Dewi Adnyani dimana kompensasi berpengaruh positif terhadap kepuasan kerja, motivasi berpengaruh positif dan signifikan terhadap kepuasan kerja, kompensasi berpengaruh positif terhadap kinerja karyawan, kepuasan kerja berpengaruh positif dan signifikan terhadap kinerja karyawan dan kepuasan kerja memediasi pengaruh kompensasi dan motivasi terhadap kinerja karyawan (Nurcahyani \& Adnyani, 2016).

Kompensasi adalah pendapatan yang berbentuk uang, barang langsung atau tidak langsung yang diterima karyawan sebagai imbalan atas jasa yang diberikan kepada perusahaan (Hasibuan, 2018).

Kompensasi merupakan suatu hal yang diterima karyawan sebagai pengganti kontribusi atas pekerjaan yang mereka lakukan di perusahaan. Upah atau gaji merupakan hal yang penting untuk semua orang, khususnya bagi mereka yang bekerja. Setiap pekerja berhak memperoleh penghasilan yang layak bagi kemanusiaan, yang dapat memenuhi kebutuhan hidupnya (Mulyapradana \& Hatta, 2016).

Kompensasi dibagi menjadi dua kategori yakni kompensasi finansial dan kompensasi non finansial. Kompensasi finansial merupakan kompensasi yang diberikan secara langsung kepada karyawan dalam bentuk upah atau gaji, bonus, komisi, dan insentif. Sedangkan kompensasi non finansial merupakan komponen yang diberikan kepada karyawan bukan dalam bentuk uang, melainkan benefit atau manfaat untuk kesejahteraan karyawan berupa jaminan sosial, asuransi kesehatan, pesangon, pensiun, lembur, liburan, bahkan pujian dan pengakuan (Mulyapradana \& Hatta, 2016). Hal senada, Simamora menjelaskan komponenkomponen dan keseluruahn program kompensasi dapat dibagi menjadi dalam bentuk kompensasi langsung dan kompensasi tidak langsung (Supatmi et al., 2013).

Kompensasi diberikan dengan tujuan memberikan rangsangan dan motivasi kepada tenaga kerja untuk meningkatkan prestasi kerja, serta efisiensi dan efektivitas produksi. Oleh karena itu, bila kompensasi diberikan secara benar, para karyawan akan lebih terpuaskan dan termotivasi untuk mencapai sasaran-sasaran organisasi (Logahan et al., 2012).

Upaya yang bisa ditempuh perusahaan diantaranya adalah dengan memotivasi karyawan melalui penerapan kompensasi yang sesuai dengan kemampuan sehingga tercapai kepuasan kerja, karyawan yang merasa terpuaskan akan lebih loyal serta kinerjanya akan meningkat dalam perusahaan (Nurcahyani \& Adnyani, 2016).

Menurut S. Pantja Djati, et. al (Setiawan et al., 2019) ada beberapa penyebab dari kepuasan dan ketidakpuasan karyawan atas kompensasi yang mereka terima, yaitu :

a. Kepuasan individu terhadap kompensasi berkaitan dengan harapan dan kenyataan terhadap sistem kompensasi. Kompensasi yang diterima tidak sesuai dengan yang diharapkan, apabila kompensasi yang diterima terlalu kecil dibandingkan dengan harapannya.

b. Kepuasan dan ketidakpuasan karyawan akan kompensasi juga timbul karena karyawan membandingkan dengan karyawan lain di bidang pekerjaan dan organisasi sejenis.

c. Karyawan sering salah persepsi terhadap sistem kompensasi yang diterapkan perusahaan.

d. Kepuasan dan ketidakpuasan akan kompensasi juga tergantung pada variasi dari kompensasi itu sendiri. 
Seseorang yang puas akan memiliki motivasi dan partisipasi kerja yang tinggi, yang pada akhirnya akan terus memperbaiki kinerja mereka. Kinerja karyawan merupakan hasil kerja baik kualitas maupun kuantitas yang dihasilkan karyawan atau perilaku nyata yang ditampilkan sesuai dengan tanggung jawab yang diberikan kepadanya (Nurcahyani \& Adnyani, 2016).

Hal ini senada dengan hasil penelitian dari $\mathrm{T}$. Wijaya dan F. Andreani, dari hasil penelitian tersebut didapatkan bahwa motivasi dan kompensasi berpengaruh positif terhadap kinerja karyawan. Diantara kedua variabel tersebut, motivasi memiliki pengaruh lebih dominan terhadap kinerja karyawan dibandingkan dengan kompensasi (Wijaya \& Andreani, 2015).

Kinerja karyawan merupakan permasalahan yang selalu dihadapi oleh pihak manajemen sebuah organisasi, oleh karena itu manajemen perlu mengetahui faktor yang mempengaruhi kinerja karyawan (Elshifa, 2018). Secara konseptual kinerja adalah hasil yang dicapai oleh seseorang dalam kurun waktu tertentu berdasarkan standar kerja yang telah ditetapkan (Supatmi et al., 2013). Menurut Rivai (Firdaus \& Mulyapradana, 2017) kinerja adalah perilaku nyata yang ditampilkan setiap karyawan sebagai prestasi kerja yang dihasilkan sesuai dengan perannya dalam perusahaan.

Menurut Mathis dan Jackson (Logahan et al., 2012), faktor-faktor yang mempengaruhi kinerja individu tenaga kerja adalah : kemampuan mereka, motivasi, dukungan yang diterima, keberadaan pekerjaan yang mereka lakukan dan hubungan mereka dengan organisasi. Sedangkan menurut Prawirosentono (Riyadi \& Mulyapradana, 2017) faktor-faktor yang mempengaruhi kinerja karyawan, yaitu:

1. Efektifitas dan efisiensi, bila suatu tujuan tertentu akhirnya bisa dicapai kita boleh mengatakan bahwa kegiatan tersebut efektif tetapi apabila akibat-akibat yang tidak dicari kegiatan menilai yang penting dari hasil yang dicapai sehingga kepuasan walaupun efektif dinamakan tidak efisien. Sebaliknya, bila akibat yang dicari-cari tidak penting atau remeh maka kegiatan tersebut efesien.

2. Otoritas (wewenang), sifat dari suatu komunikasi atau perintah dalam suatu organisasi formal yang dimiliki seorang anggota organisasi kepada anggota yang lain untuk melakukan suatu kegiatan kerja sesuai dengan kontribusinya. Perintah tersebut mengatakan apa yang boleh dilakukan dan yang tidak boleh dalam organisasi tersebut.

3. Displin, taat kepada hukum dan peraturan yang berlaku.

4. Inisiatif, berkaitan dengan daya pikir dan kreatifitas dalam membentuk ide untuk merencanakan sesuatu yang berkaitan dengan tujuan organisasi.

Menurut John Miner (Riana et al., 2017) mengemukakan bahwa dimensi dari kinerja yaitu:

a. Kualitas : menerangkan tentang jumlah kesalahan, kerusakan dan kecermatan

b. Kuantitas : jumlah pekerjaan yang dihasilkan berkenaan.

c. Waktu kerja : menerangkan tingkat kehadiran, keterlambatan, waktu kerja efektif.

d. Kerjasama dalam orang lain dalam bekerja.

Manusia adalah sumber daya yang sangat penting dalam bidang industri dan organisasi, oleh karena itu pengelolaan sumber daya manusia mencangkup penyediaan tenaga kerja yang bermutu, mempertahankan kualitas dan mengendalikan biaya ketenagakerjaan yang menjadi hal yang sangat penting. Sebagai aset yang penting bagi perusahaan hendaknya karyawan mendapatkan perhatian yang penuh dari perusahaan terutama bagi karyawan yang memiliki potensi yang unggul. Komunikasi yang baik dan umpan balik dari pihak manajemen dapat mengurangi munculnya berbagai masalah yang dapat mendorong ketidakpuasan karyawan sehingga menyebabkan keinginan untuk meninggalkan perusahaan.

Kebijakan yang dibuat oleh perusahaan hendaknya memperhatikan juga kepentingan karyawan. Perilaku penarikan diri dari organisasi pada umumnya berhubungan dengan ketidakcocokan antara apa yang diharapkan pekerja dan apa yang diberikan organisasi. Kebijaksanaan perusahaan yang tidak sesuai dengan kebutuhan dan harapan pekerja akan berdampak buruk pada sikap kerja pekerjaanya (Mulyapradana, 2012).

Dari fenomena tersebut peneliti tertarik untuk mengkaji pemberian kompensasi dan kinerja karyawan. Tujuan penelitian ini adalah untuk mengetahui pengaruh pemberian kompensasi terhadap kinerja karyawan Hotel Dafam Kota Pekalongan. 
Tabel 1. Dimensi Variabel Kompensasi dan Kinerja

\begin{tabular}{|l|ll|}
\hline \multicolumn{1}{|c|}{ Variabel } & \multicolumn{1}{c|}{ Dimensi } \\
\hline Independent Variable $(\mathrm{X}):$ & a. & Kompensasi Langsung : \\
Kompensasi & b. & Kompensasi Tidak Langsung : \\
\hline Dependent Variable $(\mathrm{Y}):$ & a. & Kualitas \\
Kinerja Karyawan & b. & Kuantitas \\
& c. & Waktu Kerja \\
& d. & Kerjasama \\
\hline
\end{tabular}

\section{METODE PENELITIAN}

Populasi adalah keseluruhan objek atau individu yang akan diteliti, memiliki karakteristik tertentu, jelas dan lengkap (Dwi Anjarini, 2018). Populasi dalam penelitian ini adalah karyawan Hotel Dafam Kota Pekalongan sebanyak 44 orang, karena jumlah populasi relatif kecil, maka seluruh populasi dijadikan sebagai sampel penelitian. Menurut Arikunto (Elshifa et al., 2019), apabila subjek penelitian berjumlah kurang dari 100 lebih baik diambil semua sehingga penelitiannya merupakan penelitian populasi atau menggunakan teknik sampling sensus dan metode kuantitatif.

\section{Kerangka Pemikirian}

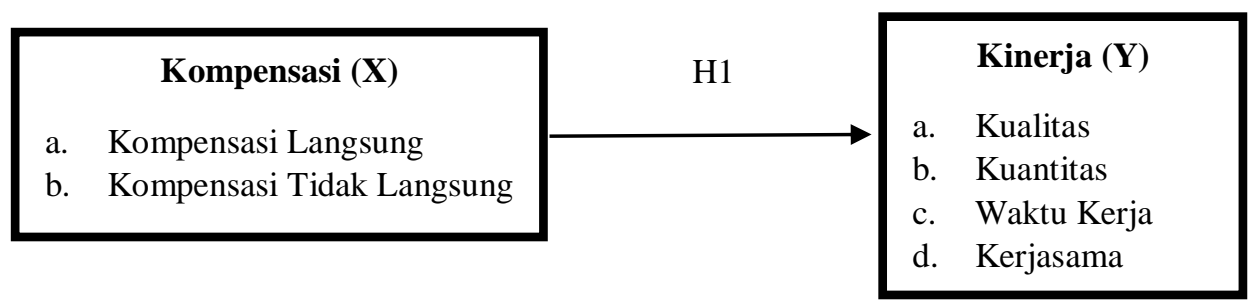

Gambar 1. Kerangka Pemikiran

Keterangan :

$\begin{aligned} \longrightarrow & : \text { Pengaruh } \\ & : \text { Kompensasi berpengaruh positif terhadap } \\ & \text { Kinerja }\end{aligned}$

Penelitian ini dilakukan untuk mengkaji pengaruh pemberian kompensasi terhadap kinerja karyawan. Dengan studi pada Hotel Dafam Kota Pekalongan. Dalam penelitian ini pemberian kompensasi berpengaruh pada kinerja karyawan. menurut E. Leonardo dan F. Andreani dalam penelitiannya menyimpulkan bahwa kompensasi finansial dan non finansial berpengaruh positif dan signifikan terhadap kinerja karyawan. Diantara kedua variabel tersebut, kompensasi finansial memiliki pengaruh lebih dominan terhadap kinerja karyawan dibandingkan dengan kompensasi non finansial (Leonardo \& Andreani, 2015)
Dengan menggunakan kuisioner yang ditujukan kepada responden yang terdiri dari sejumlah pernyataan mengenai pemberian kompensasi dan kinerja karyawan. Pernyataan-pernyataan dalam kuisioner diukur dengan menggunakan skala likert dan teknik analisa data yang dipergunakan dalam penelitian ini adalah SPSS versi 16.0.

Metode Analisis data menggunakan uji validitas, uji reliabilitas dan analisis regresi linier sederhana serta untuk mengetahui pengaruh masing-masing variabel menggunakan uji t (Sugiyono, 2016).

\section{HASIL DAN PEMBAHASAN}

\section{A. Uji Validitas}

Uji Validitas ini didasarkan pada rumus $\mathrm{r}_{\text {tabel }}$ dan taraf signifikasi pada tabel ini adalah 0,05 atau 5\% dengan jumlah sampel 44 responden. Untuk penelitian ini diperoleh $r_{\text {tabel }}$ sebagai berikut, karena peneliti menggunakan $\mathrm{N}=44$ maka $\mathrm{df}=\mathrm{n}-2, \mathrm{df}=44-2=42$ dengan demikian jika dilihat dari rtabel df $42=0,25$ dan apabila nilai ítem lebih kecil dari 0,25 maka ítem tersebut tidak valid begitupun sebaliknya.

Tabel 2. Hasil Uji Validitas Kompensasi (X)

\begin{tabular}{|l|l|l|l|}
\hline Instrumen & $r$ hitung & $r$ table & Keterangan \\
\hline
\end{tabular}




\begin{tabular}{|l|l|l|l|}
\hline item_1 & $.867^{* *}$ & 0,25 & Valid \\
\hline item_2 & $.859^{* *}$ & 0,25 & Valid \\
\hline item_3 & $.785^{* *}$ & 0,25 & Valid \\
\hline item_4 & $.798^{* *}$ & 0,25 & Valid \\
\hline item_5 & $.732^{* *}$ & 0,25 & Valid \\
\hline item_6 & $.819^{* *}$ & 0,25 & Valid \\
\hline item_7 & $.836^{* *}$ & 0,25 & Valid \\
\hline item_8 & $.836^{* *}$ & 0,25 & Valid \\
\hline item_9 & $.872^{* *}$ & 0,25 & Valid \\
\hline item_10 & $.872^{* *}$ & 0,25 & Valid \\
\hline item_11 & $.760^{* *}$ & 0,25 & Valid \\
\hline item_12 & $.538^{* *}$ & 0,25 & Valid \\
\hline
\end{tabular}

Tabel 3. Hasil Uji Validitas Kinerja (Y)

\begin{tabular}{|l|c|c|c|}
\hline Instrumen & $\mathrm{r}$ hitung & $\mathrm{r}$ table & Keterangan \\
\hline item_1 & $.734^{* *}$ & 0,25 & Valid \\
\hline item_2 & $.802^{* *}$ & 0,25 & Valid \\
\hline item_3 & $.928^{* *}$ & 0,25 & Valid \\
\hline item_4 & $.717^{* *}$ & 0,25 & Valid \\
\hline item_5 & $.790^{* *}$ & 0,25 & Valid \\
\hline item_6 & $.784^{* *}$ & 0,25 & Valid \\
\hline item_7 & $.722^{* *}$ & 0,25 & Valid \\
\hline item_8 & $.741^{* *}$ & 0,25 & Valid \\
\hline item_9 & $.928^{* *}$ & 0,25 & Valid \\
\hline item_10 & $.928^{* *}$ & 0,25 & Valid \\
\hline item_11 & $.530^{* *}$ & 0,25 & Valid \\
\hline item_12 & $.577^{* *}$ & 0,25 & Valid \\
\hline
\end{tabular}

Berdasarkan pengujian diatas dapat diketahui bahwa seluruh nilai $r$ hitung dari semua indikator memiliki hasil yang lebih besar dari pada $r$ table maka dapat disimpulkan bahwa item butir pertanyaan pada kuesioner dalam penelitian ini adalah valid.

\section{B. Uji Reliabilitas}

Uji reliabilitas dilakukan untuk mengetahui konsistensi hasil pengukuran variabel. Uji reliabilitas adalah tingkat ketepatan, ketelitian atau keakuratan sebuah instrumen. Instrumen yang sudah dapat dipercaya atau reliabel akan menghasilkan data yang dapat dipercaya juga. Suatu konstruk atau variabel dikatakan reliabel jika memberikan nilai alpha cronbach 0,60.

Tabel 4. Hasil Uji Reliabilitas

\begin{tabular}{|l|c|l|}
\hline Variabel & $\begin{array}{l}\text { Alpha } \\
\text { Cronbach }\end{array}$ & Keterangan \\
\hline Kompensasi (X) & 0.945 & Reliabel \\
\hline
\end{tabular}

\begin{tabular}{|l|c|l|}
\hline Kinerja (Y) & 0.925 & Reliabel \\
\hline
\end{tabular}

Berdasarkan uji reliabilitas dilakukan terhadap item pertanyaan yang dinyatakan valid. Suatu variabel dikatakan reliabel atau handal jika jawaban terhadap pertanyaan selalu konsisten. Jadi hasil koefisien reliabilitas vaiabel kompensasi adalah sebesar 0,945 , sedangkan variabel kinerja adalah sebesar 0.925 , ternyata memiliki nilai Alpha Cronbach lebih besar dari 0,60 yang berarti kedua variabel dinyatakan reliabel atau memenuhi persyaratan.

\section{Uji Regesi Linear Sederhana}

Analisis regresi linier sederhana adalah analisis untuk mengukur besarnya pengaruh antara satu variabel independen dengan satu variabel dependen dan memprediksi variabel dependen dengan menggunakan variabel independen. Hubungan antara variabel $\mathrm{Y}$ dan variabel $\mathrm{X}$ dapat linear atau bukan linear.

Tabel 5. Hasil Analisis Linear Sederhana

\begin{tabular}{|c|c|c|c|c|c|c|}
\hline & & \multicolumn{2}{|c|}{$\begin{array}{l}\text { Unstandardized } \\
\text { Coefficients }\end{array}$} & $\begin{array}{l}\text { Standardized } \\
\text { Coefficients }\end{array}$ & $\mathrm{t}$ & Sig. \\
\hline \multicolumn{2}{|c|}{ Model } & B & Std. Error & Beta & & \\
\hline \multirow[t]{2}{*}{1} & (Constant) & 12.379 & 3.012 & & 4.109 & .000 \\
\hline & Kompensasi & .734 & .059 & .886 & 12.406 & .000 \\
\hline
\end{tabular}

a. Dependent Variable:

Kinerja

Berdasarkan Pada hasil analisis yang telah dilakukan, maka bersamaan regresi yang terbentuk adalah sebagai berikut:

$$
\begin{aligned}
& \mathrm{Y}=\mathrm{a}+\mathrm{bx} \\
& \mathrm{Y}=12.379+0.734 \mathrm{x}
\end{aligned}
$$

$$
\begin{aligned}
& \text { Dimana: } \\
& \mathrm{Y}=\text { Kinerja karyawan } \\
& \mathrm{X}=\text { Kompensasi karyawan } \\
& \mathrm{a}=\text { konstant } \\
& \mathrm{b}=\text { koefisen garis regresi }
\end{aligned}
$$

Dari persamaan diatas dapat dijelaskan sebagai berikut:

a) Konstanta sebesar 12.379 menunjukkan nilai kinerja sebelum dipengaruhi oleh variabel kompensasi adalah positif.

b) Koefisien $\mathrm{b}=0,734$ menunjukkan setiap peningkatan 1 skor kompensasi akan meningkatkan kinerja kayawan sebesar 0,734 dengan asumsi 
variabel-variabel bebas lainnya konstan. Nilai koefisien regresi pada variabel kompensasi bertanda positif, artinya terjadi pengaruh positif atau searah antara kompensasi dengan kinerja karyawan.

\section{Uji t (Parsial)}

Uji t ini digunakan untuk mengetahui apakah variabel independen berpengaruh secara signifikan atau tidak terhadap variabel dependen. Pengujian dilakukan menggunakan tingkat signifikasi 0,05 .

Tabel 6. Hasil Uji t (Parsial)

\begin{tabular}{|c|c|c|c|c|c|}
\hline \multirow[b]{2}{*}{ Model } & \multicolumn{2}{|c|}{$\begin{array}{l}\text { Unstandardized } \\
\text { Coefficients }\end{array}$} & \multirow{2}{*}{ 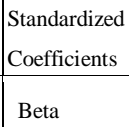 } & \multirow[b]{2}{*}{$\mathrm{T}$} & \multirow[b]{2}{*}{ Sig. } \\
\hline & B & Std. Error & & & \\
\hline (Constant) & 12.379 & 3.012 & & 4.109 & .000 \\
\hline Kompensasi & .734 & .059 & .886 & 12.406 & .000 \\
\hline
\end{tabular}

a. Dependent Variable:

Kinerja

Berdasarkan data di atas, maka dapat dilakukan pengujian hipotesis dengan cara membandingkan $t_{\text {tabel }}$ dengan nilai $t_{\text {hitung }}$ sebagai berikut:

a. Jika $t_{\text {hitung }}>t_{\text {tabel}}$, maka Ho ditolak.

b. Jika $t_{\text {hitung }}<t_{\text {tabel }}$, maka Ho diterima.

Untuk mengetahui nilai $t_{\text {tabel}}$, maka perhitungan didasarkan pada derajad keabsahan $\mathrm{df}=\mathrm{n}-2$ yakni 44-2 $=42$ dengan taraf signifikansi 0,05 atau 5\%.

$$
\begin{aligned}
& \mathrm{t}_{\text {tabel }}: 1,681 \\
& \mathrm{t}_{\text {hitung }}: 12.406
\end{aligned}
$$

Dari uji $\mathrm{t}$ di atas terdapat nilai $\mathrm{t}_{\text {hitung }}$ sebesar 12.406 dan nilai signifikansi 0,000. Dikarenakan nilai $\mathrm{t}_{\text {hitung }} 12.406>\mathrm{t}_{\text {tabel }} 1,681$ dan nilai signifikansi $0,000<$ 0,05 maka data dinyatakan signifikan. Dengan ini, maka hipotesis Ha diterima kebenarannya karena thitung lebih besar dari $t_{\text {tabel. }}$ Disimpulkan bahwa variabel kompensasi berpengaruh positif signifikan terhadap kinerja karyawan di Hotel Dafam Pekalongan.

\section{E. Uji Koefisien Determinasi}

Koefisien determinasi pada intinya mengukur seberapa jauh kemampuan variabel independen dalam menerangkan variansi variabel dependen. Nilai koefisien determinasi adalah antara nol dan satu. Penelitian ini menggunakan nilai $\mathrm{R}$ Square untuk mengevaluasi model regresi. Nilai R Square mampu naik atau turun apabila satu variabel independen ditambahkan dalam model regresi.

Tabel 7.

Hasil Analisis Koefisien Determinasi

\begin{tabular}{|c|c|c|c|}
\hline $\mathrm{R}$ & R Square & $\begin{array}{c}\text { Adjusted R } \\
\text { Square }\end{array}$ & $\begin{array}{c}\text { Std. Error of } \\
\text { the Estimate }\end{array}$ \\
\hline $.886^{\mathrm{a}}$ & .786 & .780 & 2.69483 \\
\hline
\end{tabular}

a. Predictors: (Constant), Kompensasi

Berdasarkan tabel diatas, diketahui bahwa koefisien determinasi memiliki R Square sebesar 0,786. hal ini berarti $79 \%$ kinerja (Y) yang dapat dijelaskan oleh variabel independen yaitu kompensasi. Sisanya yaitu $21 \%$ dijelaskan oleh variabel lainnya yang tidak diteliti dalam penelitian ini.

\section{KESIMPULAN}

Hasil dari pembahasan dan analisa dalam penelitian ini dapat ditarik kesimpulan yakni hasil penelitian ini menunjukkan bahwa pemberian kompensasi berpengaruh signifikan terhadap kinerja karyawan Hotel Dafam Kota Pekalongan dengan nilai koefisien 0,734 artinya terjadi pengaruh positif atau searah antara kompensasi dengan kinerja karyawan dengan $t_{\text {hitung }}$ sebesar 12.406 dan nilai signifikansi 0.000. dikarenakan nilai thitung $12.406>$ ttable 1.681 dan nilai signifikansi $0.000<0.05$ maka data dinyatakan signifikan maka hipotesa $\mathrm{Ha}$ diterima kebenarannya karena $t_{\text {tabel }}$ lebih besar dari rtabel.disimpulan bahwa variabel kompensasi berpengaruh terhadap berpengaruh positif signifikan. Adapun validitas dan realibilitas untuk skala kompensasi berkisar dari 0.538 sampai 0.872 dan koefisien reliabilitas 0.945 dengan $r$ tabel yaitu $\mathrm{N} 42$ adalah 0.25 (5\%). Dan skala kinerja diperoleh kisaran 0.530 sampai 0.928 dan koefisien reliabilitas 0.925 dengan $r$ tabel yaitu N 42 adalah $0.25(5 \%)$.

Berdasarkan hasil penelitian yang terkait dengan kompensasi dan kinerja karyawan maka disarankan agar perusahaan mampu meningkatkan dan menjaga kinerja karyawan tetap optimal dengan cara sistem pemberian kompensasi yang baik akan mampu meningkatkan kinerja karyawan sehingga berdampak pada kepuasan bagi karyawan dan dapat mempertahankan karyawan serta meningkatkan kesejahteraan karyawan. Dari hasil data yang diperoleh perusahaan disarankan untuk mempertahankan sistem pemberian kompensasi langsung dan memperhatikan pemberian kompensasi tidak langsung kepada karyawan seperti mengadakan kegiatan berlibur Bersama atau employee garthering, adanya jaminan 
kesehatan, bonus dan pemberian tunjangan untuk karyawan. Dengan memperhatikan sistem pemberian kompensasi langsung dan tidak langsung diharapkan kinerja karyawan menjadi optimal agar tercapai tujuan yang diharapkan oleh perusahaan. Secara keseluruhan kinerja karyawan di Hotel Dafam Kota Pekalongan di kategorikan baik namun agar kinerja karyawan tetap optimal dan meningkat maka perusahaan harus memperhatikan aspek-aspek seperti kualitas, kuantitas, waktu kerja dan kerjasama.

Berdasarkan hasil pengujian koefisien determinasi memiliki R Square sebesar 0.786, hal ini berarti $78 \%$ kinerja dipengaruhi oleh kompensasi dan $21 \%$ sisanya dipengaruhi oleh faktor lain yang tidak diteliti dalam penelitian ini.

\section{REFERENSI}

Dwi Anjarini, A. (2018). Analisis Pengaruh Emotional Quotient, Intelligence Quotient dan Spiritual Quotient Terhadap Kepuasan Kerja dan Kinerja Guru di Sekolah Luar Biasa Negeri Batang. BBM (Buletin Bisnis \& Manajemen), 3(1), 28-40.

Elshifa, A. (2018). Pengaruh Leader Member Exchange (LMX) dan Komitmen Organisasi terhadap Kinerja Karyawan dengan Mediasi Organizational Citizenship Behavior (OCB) (Studi Kasus pada Karyawan Kospin Jasa Pekalongan). Ecomomicus, 9(1), 25-39.

Elshifa, A., Anjarini, A. D., \& Kharis, A. J. (2019). Pengaruh Quality Of Work Life Dan Penggunaan Teknologi Informasi Terhadap Perilaku Kerja Inovatif Dosen Yang Dimediasi Komitmen Organisasi ( Studi pada Dosen Politeknik Pusmanu Pekalongan ). Ecomomicus, 10(2), 189200.

Firdaus, R. M., \& Mulyapradana, A. (2017). Pengaruh Modal Sosial dan LMX terhadap Kinerja melalui Komitmen Organisasi. Buletin Bisnis \& Manajemen, 3(2), 1-13.

Hasibuan. (2018). Manajemen Sumber Daya Manusia. In Manajemen Sumber Daya Manusia.

Leonardo, E., \& Andreani, F. (2015). Pengaruh Pemberian Kompensasi Terhadap Kinerja Karyawan Pada PT. Kopanitia. Geophysical Research Letters. https://doi.org/10.1029/GL008i001p00077

Logahan, J. M., Tjoe, T. F., \& Naga, N. (2012). Analisis Pengaruh Lingkungan Kerja dan Pemberian Kompensasi terhadap Kinerja Karyawan CV Mum Indonesia. Binus Business Review. https://doi.org/10.21512/bbr.v3i1.1344

Mujibul, M., \& Hakim, R. F. (2019). Analisis Kinerja Karyawan Studi Kasus Pt. Reycom Dokumen Solusi.

Mulyapradana, A. (2012). Universitas Indonesia Terhadap Intensi Turnover Karyawan.

Mulyapradana, A., \& Hatta, M. (2016). Jadi Karyawan Kaya; Genius Mengetahui \& Mengelola Hak Keuangan Karyawan (L. Sutinah (ed.); 1st ed.). Visimedia.

https://visimediapustaka.com/buku/jadi-

karyawan-kaya-genius-mengetahui-mengelola-

hak-keuangan-karyawan/

Nurcahyani, N., \& Adnyani, I. (2016). Pengaruh Kompensasi Dan Motivasi Terhadap Kinerja Karyawan Dengan Kepuasan Kerja Sebagai Variabel Intervening. E-Jurnal Manajemen Universitas Udayana.

Riana, N., Fajri, K., \& Alsyaumi, K. (2017). Pengaruh Kompensasi Terhadap Kinerja Karyawan Di Kampung Batu Malakasari Tektona Waterpark Kabupaten Bandung. Tourism Scientific Journal. https://doi.org/10.32659/tsj.v2i1.15

Riyadi, S., \& Mulyapradana, A. (2017). Pengaruh Motivasi Kerja Terhadap Kinerja Guru Radhatul Atfal di Kota Pekalongan. Jurnal.Pekalongankota.Go.Id.

Setiawan, S., Ekonomi, J., Syariah, E., \& No, V. (2019). Peran Work Motivation Sebagai Variabel Intervening Pengaruh Instrinsic Reward , Supervision Of Work \& Statisfaction Of Compensation Terhadap Employee Performance ( Studi pada Koperasi Kota Pekalongan ). 2(1), 115-125.

Sugiyono. (2016). Metodologi Penelitian Kuantitatif, Kualitatif, dan R\&D. In CV Alfabeta. https://doi.org/https://doi.org/10.3929/ethz-b000238666

Supatmi, M. E., Nimran, U., \& Utami, H. N. (2013). Pengaruh Pelatihan, Kompensasi terhadap Kepuasan Kerja Karyawan dan Kinerja Karyawan. Jurnal Profit. https://doi.org/10.9876/10.9876/VOL1ISSN197 $8-743 \mathrm{X}$

Wijaya, T., \& Andreani, F. (2015). Pengaruh Motivasi Dan Kompensasi Terhadap Kinerja Karyawan Pada Pt Sinar Jaya Abadi Bersama. Agora. 